\title{
Writing for publication; reconceptualizing disengagement
}

Whilst undertaking Professional Doctorate, the author explored the issue of writing for publication. She showed evidence that barriers to writing exist and competing demands impinge upon the ability to engage with the process. One suggestion is to consider the work of Murray (2013) who proposes the reconceptualization of the commonly held belief that disengagement from competing work is required in order to write.

\section{Writing for Publication; Literature}

Educational authors offer: guidelines, strategies, methods, approaches, hints, tips, structures and formats for writing for publication. When synthesized, they propose the following strategies: finding time and space to write, planning the work, selecting an appropriate journal for submission, considering the structure and content, engaging in peer review feedback.

However, research suggests that barriers to writing exist, including those related to energy and confidence, perceived knowledge and skills and environmental barriers (WRIGHT ST-CLAIR; HOCKING, 2005). Dwyer et al. (2015) suggest reframing these barriers. Murray's (2013) research challenges us to re-conceptualize the notion of how we think about writing for publication. This author took up the challenge and explored "reconceptualizing disengagement". Murray (2013) suggests that scholars move between series of engagements and disengagements. Disengagement from other activities (MAYRATH, 2008) is necessary to success in publishing, and competing demands from the academic work can represent an impediment to writing (MACLEOD; STECKLEY; MURRAY, 2012). Murray's Model of Disengagement (2013) suggests considering that engagement involves:

- Social engagement: moving from competitive to social and shared writing.

- Physical engagement: moving from the office space to dedicated writing time and space.

- Cognitive engagement: moving from fear and anxiety to making time and space and to legitimizing writing.

She challenges institutions to avoid expecting staff to "write" in due time like a hobby, stating that "[...] all respondents associated academic writing with disengagement from other tasks [...]" (MURRAY, 2013, p. 81).

\section{You Can Reflect Using Murray's (2013) Model of Disengagement}

Murray's three components may well have relevance to you and your motivation and ability to write for publication. How can you engage with the process of writing for publication? You can find many guidelines and suggestions but considering Murray's model may well help you understand how to engage with the process.

Consider your social engagement with writing. Some people like "buddies" or critical friends to offer feedback and help. Social engagement does not necessarily mean face to face interactions; this could include phone calls or Skype meetings. This social writing sustains commitment and motivation, according to Murray (2013).

Secondly, think about your physical engagement with writing. Where do you work best? Murray suggests we must consider our physical environment. For example, shared office space may be unsuitable for writing for publication. Furthermore, constant demand to respond to "urgent" requests can be 
overwhelming. "Fire-fighting" is pervasive. It is helpful to find the physical space best for the writer, i.e., a place where the writer works best. This can be freeing and the move towards engaging with this new physical space is usually positive.

Finally, consider cognitive engagement. In Murray's study, $75 \%$ of the sample mentioned this issue and highlighted fear and anxiety related to tasks left incomplete or missed in order to disengaging to write. Think about legitimizing writing; one needs to allow or legitimize writing for oneself. In addition, psychological disengagement was an issue raised by participants. This means to allow oneself to write and to establish priorities. It was suggested that cognitive disengagement may be difficult to be achieved because "writing" has not been included or given relevance in workloads. Murray (2013) also suggested that the staff often attempts to write in working environments designed for other tasks.

\section{Summary and Conclusion}

This brief editorial offered a foundation of initial evidence to re-conceptualize the act of disengaging with some responsibilities in order to participate in writing, by considering:

- A change towards the view that "writing" needs to be perceived in a positive light;

- A change of view that the activity of disengaging from general work is seen in a negative light;

- That the social, physical and cognitive engagement components clarify this process and offer a helpful alternative understanding.

Murray's (2013) theory has offered: a reconceptualization of the belief that one needs to disengage from competing tasks in order to write. It is suggested that one should engage with the social, cognitive and physical components of writing. So, act with this knowledge and find your own social, physical and cognitive engagement with writing for publication.

\section{References}

DWYER, T. et al. A proactive approach to increasing academics' writing skills and outcomes. Nurse Education in Practice, Oxford, v. 15, n. 4, p. 321-326, 2015. http://dx.doi.org/10.1016/j.nepr.2014.12.004.

MACLEOD, I.; STECKLEY, L.; MURRAY, M. Time is not enough: promoting strategic engagement with writing for publication. Studies in Higher Education, Australia, v. 37, n. 5, p. 641-645, 2012.

MAYRATH, M. Attributions of productive authors in educational psychology journals. Educational Psychology Review, New York, v. 20, n. 1, p. 41-56, 2008.

MURRAY, R. "It's not a hobby": re-conceptualizing the place of writing in academic work. Higher Education, Dordrecht, v. 66, n. 1, p. 79-91, 2013.

WRIGHT ST-CLAIR, V.; HOCKING, C. Communicating through publishing: a professional mandate. New Zealand Journal of Occupational Therapy, New Zealand, v. 52, n. 2, p. 5-8, 2005.

\section{Linda Renton}

Queen Margaret University, Edinburgh, UK.

e-mail: 1renton@qmu.ac.uk 